\title{
Stage III Thyroid Gland Medullary Carcinoma AJCC v8
}

National Cancer Institute

\section{Source}

National Cancer Institute. Stage III Thyroid Gland Medullary Carcinoma A/CC v8. NCI

Thesaurus. Code C141045.

Stage III includes: T1-3, N1a, M0. T1: Tumor measuring $2 \mathrm{~cm}$ or less in greatest dimension limited to the thyroid. T2: T umor measuring more than $2 \mathrm{~cm}$ but less than 4 $\mathrm{cm}$ in greatest dimension limited to the thyroid. T3: Tumor measuring $4 \mathrm{~cm}$ or more in greatest dimension or with extrathyroidal extension. N1a: Metastasis to level VI or VII (pretracheal, paratracheal, or prelaryngeal/Delphian, or upper mediastinal) lymph nodes. This can be unilateral or bilateral disease. M0: No distant metastasis. (from AJCC 8th Ed.) 